\title{
MECHANICAL AND MORPHOLOGICAL PROPERTIES OF POLY(3-HYDROXYBUTYRATE)-THERMOPLASTIC STARCH/CLAY/EUGENOL BIONANOCOMPOSITES
}

\author{
KARLA A. GARRIDO-MIRANDA ${ }^{a}$, BERNABÉ L. RIVAS ${ }^{a *}$, MÓNICA PÉREZ-RIVERA ${ }^{a}$, \\ JUAN P. FERNÁNDEZ-BLAZZUUEZ ${ }^{b}$, MIGUEL MONCLÚS ${ }^{b}$ AND CARLOS PEÑA-FARFAL ${ }^{c}$ \\ ${ }^{a}$ Departamento de Polimeros, Facultad de Ciencias Químicas, Universidad de Concepción, Casilla 160-C, Concepción, Chile. \\ ${ }^{b} I M D E A$ Materials Institute, Calle Eric Kandel 2, 28906 Getafe, Madrid, Spain. \\ ${ }^{c}$ Instituto de Ciencias Químicas Aplicadas, Facultad de Ingeniería, Universidad Autónoma de Chile, Av. Alemania 01090, 4810101-Temuco, Chile.
}

\begin{abstract}
Food packaging for traditional foods mainly serves to isolate foods from external environmental. For this reason, it is a growing interest in developing active packaging materials that can extend foodstuff shelf-life. Also, it could counteract the level of contamination by plastic in the environment using biodegradable polymers.

For this purpose, poly(3-hydroxybutyrate) (PHB)-thermoplastic starch (TPS)/ organically modified montmorillonite (OMMT)/eugenol bionanocomposites were prepared by melt blending. Morphology, thermal, and mechanical properties were determined by comparing the concentration influence of eugenol and clay on the PHB-TPS blend and PHB. X-ray diffraction measurements revealed the existence of exfoliated morphology in the bionanocomposites. Atomic force microscopy imaging (AFM) showed the difference in morphological characteristics of the pure PHB and the prepared bionanocomposites. Roughness analysis from the AFM data indicates that the presence of clay and TPS increases the roughness with respect to PHB. Dynamic mechanical thermal analysis (DMTA) showed that bionanocomposites have an improved storage module. Finally, properties such as hardness and elastic modulus studied by nanoindentation showed a decrease with respect to PHB. The presence of eugenol in the bionanocomposites does not show a significant effect on the different properties.
\end{abstract}

Keywords: Clay, biodegradable polymers, thermoplastic starch, bionanocomposites.

\section{INTRODUCTION}

More than half a century ago, synthetic polymers like plastics have come to replace other materials such as metals, wood, glass, and cardboard, due to its great versatility, good physical properties, excellent barrier, facility for its manufacture ${ }^{1}$ and its low production cost. In 2018 the world production of plastic was approximately 359 million tons according to the latest report of the Association of Plastics Manufacturers. ${ }^{2}$ In Europe, the sectors that were most in demand were the packaging industry with $40 \%$, the construction area with $20 \%$ and the household goods, sports, health and safety ${ }^{3}$ area with $17 \%$. These three areas are the most plastic consuming. Although plastics have improved the quality of life of people due to their different applications (construction, home, textile, agriculture, among others), the plastics have some disadvantages: theyare obtained from non-renewable resources (petroleum) and can take years to degrade. Because the excellent properties of plastics make them resistant to different factors such as temperature, pressure, chemical solvents, UV light, among others. This high resistance leads to significant accumulations of plastic waste, ${ }^{4}$ which leads to environmental problems in the short and long term. In recent years progress has been made in environmental awareness by using less plastic, reusing or recycling. Still, as it is a versatile material with millions of applications, it is not an option to stop using it. Therefore, current research is concentrated on starting to use biodegradable polymers, to reduce problems such as waste accumulation, and changing the source to a renewable one.

The advantages that biodegradable polymers are obtained from natural resources and besides, these could replace synthetic polymers and solve the environmental problem produced by plastic waste, since biodegradable polymers are degraded by the action of microorganisms of natural origin such as bacteria, fungi and algae through the activity of enzymes and/or by chemical decomposition (ASTM D6400). ${ }^{5}$ To increase the use of biodegradable polymers in the plastics industry is necessary to improve properties such as brittleness, high gas permeability, low melt viscosity, among others. These disadvantages have limited its applications; therefore, it is sought to improve its properties to match those of synthetic polymers. For this reason, various lines of research are being developed, which so far have focused on mixing biodegradable polymers or nano-reinforcing them (bionanocomposites). The latter has proved to be the most effective way. ${ }^{6}$

Most poly(hydroxyalkanoates)/clays as bionanocomposites are focused to the poly(hydroxybutyrate-co-valerate) (PHBV) as it has a larger processing window than poly(hydroxybutyrate) (PHB). PHBV/clay ${ }^{7,8}$ bionanocomposite has been determined that the reduces thermal degradation, increases the degree of crystallinity, improves Young's modulus, and the deformation at break of the PHBV with the incorporation of $3 \%$ of clay. ${ }^{10}$ For the PHB bionanocomposite the results show that there is a nucleating effect by the different clays studied Namontmorillonite and 30B-montmorillonite (organically modified montmorillonite) since both increased the elastic modulus of PHB (obtained by melt mixing) ${ }^{11}$ Mechanical properties have also been improved such as the storage module which has increased by $85 \% .{ }^{12}$ On the other hand, it has been determined that there is a minimal effect on the degree of crystallization and melting temperature when working with clays such as Na-montmorillonite and modified montmorillonite (Cloisite ${ }^{15} 15 \mathrm{~A}$ and C93A). ${ }^{13}$ The clays not only improve the mechanical, thermal and barrier properties of the polymers but also make it possible to encapsulate active ingredients, which give new features to the polymers such as antioxidant, antibacterial or antifungal activity. ${ }^{14-18}$

Essential oils are active ingredients that manage to deliver antioxidant, antibacterial and antifungal activity at the same time. Among the most used essential oils are carvacrol, thymol, and eugenol, which have been used in bionanocomposites of clay, where it has been proven that it maintains its excellent antifungal properties against Botrytis cinerea. ${ }^{17,19}$ The antioxidant activity of bionanocomposites with essential oils has been tested against the DPPH (2,2-diphenyl-1-picrylhydrazyl) radical. ${ }^{17,20}$

This study aimed of this study was to obtain bionanocomposites of PHB-TPS (thermoplastic starch)/clay/ Eugenol by melt mixing in an extruder. The materials were characterized by Dynamic mechanical thermal analysis (DMTA), Nanoindentation, Atomic Force Microscopy (AFM), and X-ray diffraction (XRD). The influence of clay and eugenol concentration on the properties of the PHB-TPS blend and PHB were studied.

\section{EXPERIMENTAL}

\subsection{Materials}

Poly(hydroxybutyrate) (PHB)was purchased from Biomer Ltd. (Krailling, Germany). Corn starch (composed of $25 \%$ amylose and $75 \%$ amylopectin) was supplied by Sigma-Aldrich, technical-grade glycerol, organically modified montmorillonite (OMMT) Nanomer I.34TCN, montmorillonite clay surfacemodified with 25-30 wt \% methyl-dihydroxyethyl- hydrogenated tallow 
ammonium and eugenol, natural (98\%) were supplied by Sigma-Aldrich (Arlington Heights, Illinois, United States).

\subsection{Preparation of thermoplastic starch}

Thermoplastic starch was prepared by mixing starch, water, andglycerol in a composition of 60:15:25 (wt/wt/wt), respectively. The processingwas carried out in a co-rotating twin-screw extruder with L/ D ratio of 24 (Gülnar Makina), using a temperature profile of $90,100,110$, and $110^{\circ} \mathrm{C}$, and the screw speed set at 60 rpm.

\subsection{Preparation of Bionanocomposites}

The bionanocomposites and blends were prepared by melt intercalation in a co-rotating twin-screw extruder (Gülnar Makina) with a L/D ratio of 24 and a temperature profile of $100,140,160$, and $150^{\circ} \mathrm{C}$, and the screw speed was set at $60 \mathrm{rpm}$. The materials (PHB and TPS) were dried at $80{ }^{\circ} \mathrm{C}$ and $40{ }^{\circ} \mathrm{C}$ respectively, for at least $12 \mathrm{~h}$ before processing.

\subsection{Characterization Techniques}

\subsubsection{X-ray diffraction}

$\mathrm{X}$-ray diffraction (XRD) measurement was carried out on the diffractometer (Empyrean, Panalytical) with $\mathrm{Cu} \mathrm{K} \alpha$ radiation resources $(\lambda=1.5418 \AA)$ at room temperature in the range of $2-40^{\circ}(2 \theta)$.

\subsubsection{Atomic Force Microscopy (AFM)}

Atomic Force Microscopy (AFM) was used to determine surface topography and roughness of the samples. AFM analyses were performed on a non-contact mode AFM microscopePark XE150 (Park Systems, South Korea). Images were acquired with $10 \mu \mathrm{m} \times 10 \mu \mathrm{m}$ sizes.

\subsubsection{Nanoindentation}

The surface mechanical properties of the PHB, PHB-starch blend and the bionanocomposites were determined by using the Triboindenter 950 (Hysitron Inc., Minneapolis, USA) equipped with a Berkovich diamond indenter. The tests were performed in load control mode, at an imposed maximum load of $12.5 \mathrm{mN}$, using a constant loading rate of $\dot{\varepsilon}=\dot{p} / p=0.1 \mathrm{~s}^{-1}$, where $p$ is the load and $\dot{p}$ is the loading rate. The hold time at maximum load was $30 \mathrm{~s}$ and the unloading time was 5 seconds. Arrays of $5 \times 5$ indentations were performed on the samples, with a spacing between indents of $40 \mu \mathrm{m}$ in both vertical and horizontal directions.

The hardness and elastic modulus were calculated from the recorded loaddisplacement curves (a method developed by Oliver and Pharr). ${ }^{21}$ The elastic modulus (E) was obtained from the initial slope of the load versus displacement curve, according to equations 1 and 2 .

$$
\frac{1}{E_{r}}=\frac{1-v^{2}}{E}+\frac{1-v_{i}^{2}}{E_{i}}(1) \quad E_{r}=\frac{\sqrt{\pi} S_{\max }}{2 \sqrt{A}}
$$

where $\mathrm{Er}$ is the reduced modulus, $\mathrm{E}$ the elastic modulus, and $v$ and $v_{\mathrm{i}}$ are the Poisson proportions of the material, the corresponding values for the diamond tip are $\mathrm{E}_{\mathrm{i}}(1140 \mathrm{GPa})$ y $v_{\mathrm{i}}(0,07){ }^{22} \mathrm{In} \mathrm{Eq} .2$, " $\mathrm{S}_{\max }$ " is the slope of the discharge curve $\mathrm{dP} / \mathrm{dh}$ at the beginning of the discharge, and $\mathrm{A}$ is the contact area between the material and the maximum load of the indenter.

On the other hand, the hardness was determined, which corresponds to the maximum point (Pmax) of the curve load-displacement (eq. 3).

$$
H=\frac{P_{\max }}{A}
$$

\subsubsection{Dynamic Mechanical Thermal Analysis (DMTA)}

Dynamic-mechanical thermal properties have been determined with a TA Instrument DMTA Q 800 operating in tension mode with an oscillation frequency of $10 \mathrm{~Hz}$ and a deformation amplitude of $0.1 \% \mathrm{~s}$. Data were recorded from $-140^{\circ}$ to $100{ }^{\circ} \mathrm{C}$ at a scanning rate of $2{ }^{\circ} \mathrm{C} \mathrm{min}^{-1}$. The dependence of the storage module $\left(\mathrm{E}^{\prime}\right)$, loss module $\left(\mathrm{E}^{\prime \prime}\right)$, and loss factor (Tan Delta) with the temperature were analyzed by DMTA.

\section{RESULTS AND DISCUSSION}

\subsection{Analysis of morphological and surface properties.}

To verify that the bionanocomposites and some effect of eugenol on them were obtained. X-ray diffraction was performed for different bionanocomposites with and without eugenol to PHB and PHB-ATP blends. The diffractograms obtained are summarized in figure 1.

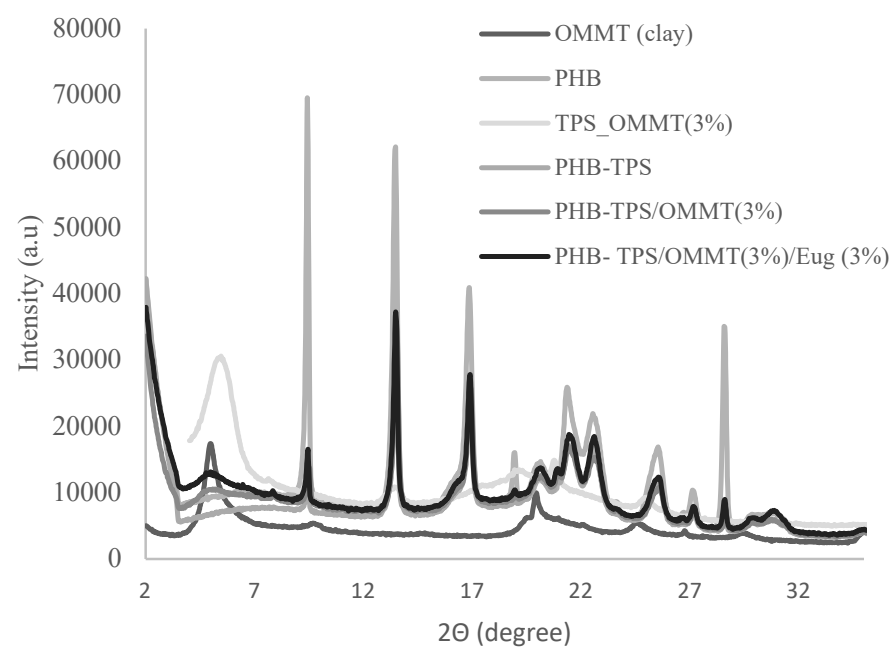

Figure 1. XRD patterns of clay (OMMT), PHB, PHB-TPS blend, and bionanocomposites with $1 \%$ and $5 \% \mathrm{wt} / \mathrm{wt}$ of clay.

The PHB diffractogram (see Figure 1) shows characteristic peaks at $16.9^{\circ}$ $(020), 18.9^{\circ}(110), 21.3^{\circ}(101)$, and $22.6^{\circ}(111)^{23,24}$ with their respective Miller index (crystallographic plane). The intensity of the characteristic peaks of PHB decreases in the case of the mixture and the bionanocomposites. This difference can be explained by analyzing the intensity ratio of the planes $(020) /(110)$, which for PHB has a value of 2.50 and for the mixture of 3.22. The increased rate means that the crystalline structure of the PHB has been disturbed as a result of the formation of hydrogen bonds. ${ }^{25}$

The diffractogram of the clay shows its characteristic peak at $4.21^{\circ}$ in the case of bionanocomposites with and without eugenol do not show the peak of the clay, which could indicate that the bionanocomposites could present an exfoliated morphology, as a consequence of the excellent interaction between the polymers and the clay layers. This interaction would allow the polymeric matrix to be incorporated between the clay layers, separating them completely. ${ }^{26}$ Furthermore, it can be concluded that the presence of eugenol does not affect the obtaining of bionanocomposite. For the PHB and PHB- TPS blend, the beginning of a peak at $3.6^{\circ}$ and another peak at $9^{\circ}$ are observed. These correspond to the trace signal of inorganic material (talc) ${ }^{23}$ presented by the commercial PHB

The surface films texture and roughness of the blown films were also analyzed by Atomic force microscopy, AFM which is a technique to analyze the surface of polymeric materials, in which two-dimensional (2D) and three-dimensional (3D) topographic images were obtained. The images obtained for PHB, the mixture PHB-TPS and the bionanocomposites PHB- TPS /OMMT (3\%), PHBTPS /OMMT (3\%)/ Eug (2.5\%) and PHB- TPS /OMMT (3\%)/ Eug (3\%). Figure 2 a) corresponds to the PHB, which has a relatively smooth surface and a maximum height of $180.3 \mathrm{~nm}$. The blend PHB-TPS presents a height of 315.8 $\mathrm{nm}$, which would indicate the presence of some disorder in the surfaces of the polymer film. ${ }^{27}$ The disorder could be attributed to the presence of the starch granules or poor homogeneity among the polymers. ${ }^{27}$

In bionanocomposites, the disorder on the surface is associated with the presence of clay, since it has been determined that when there is not a good polymer-clay interaction the clay tends to migrate towards the surface, which increases the roughness ${ }^{28}$ producing an increase in height, this could indicate that if bionanocomposites present not only an exfoliated morphology but also an interspersed morphology, which is common to observe when the bionanocomposites are obtained by mixing in melt. ${ }^{29}$ 

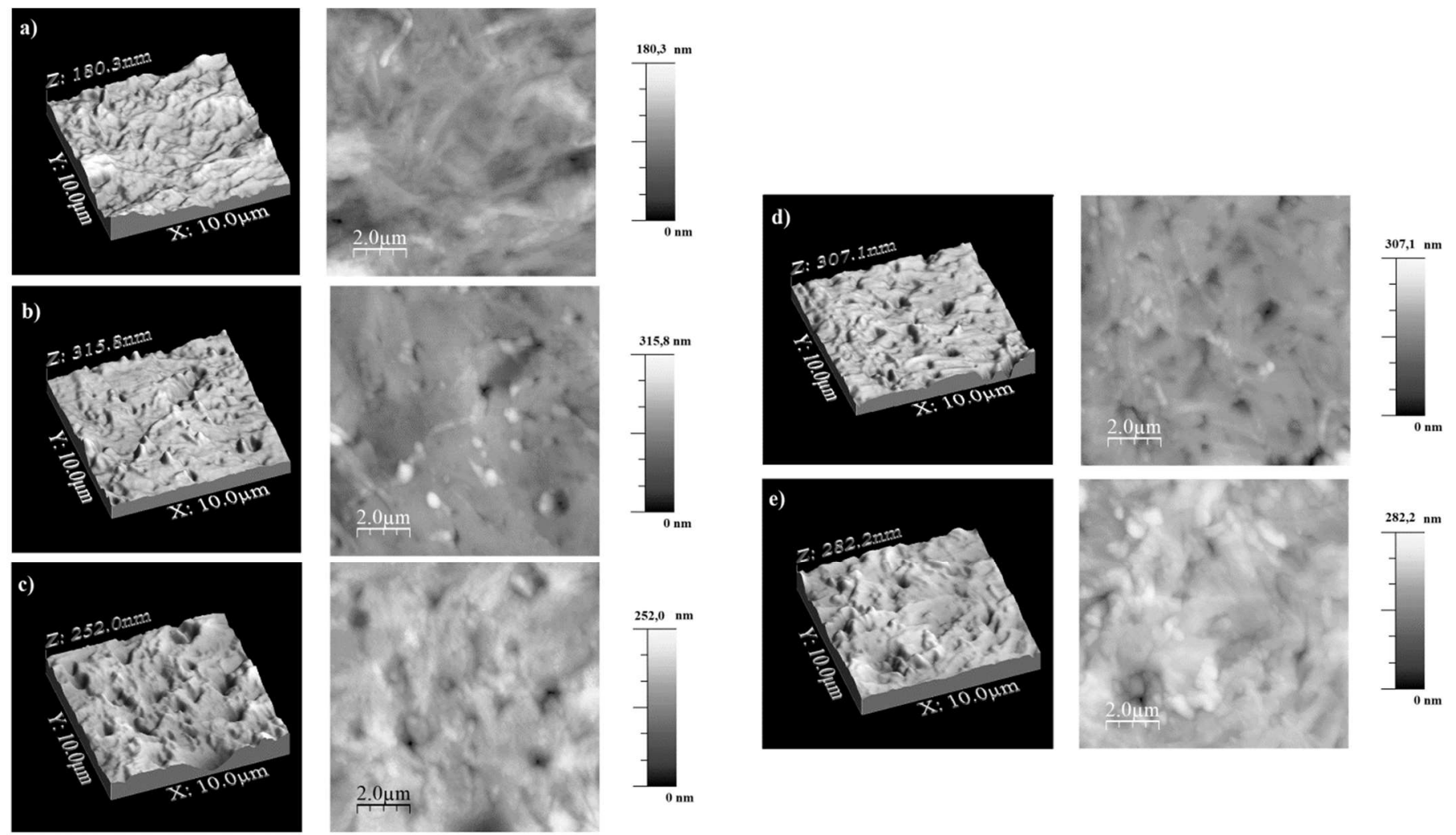

Figure 2. 3D and 2D topographic images obtained by AFM for a) PHB, b) PHB-TPS, C) PHB- TPS /OMMT(3\%), d) PHB- TPS /OMMT(3\%)/Eug (2.5\%),and e) PHB- TPS /OMMT(3\%)/Eug (3\%).

The values of mean surface roughness (Ra) and root mean square (RMS) roughness are shown in Table 1. The PHB has a surface roughness of 13.0 5.3 $\mathrm{nm}$, the PHB- TPS blend of $18.9 \pm 2.9 \mathrm{~nm}$, and the bionanocomposites of $21.6 \pm 2.4$ $\mathrm{nm}$, respectively. The higher roughness value of the bionanocomposites is associated with the influence of the clay, since it migrates towards the surface of the polymeric material as a result of weak interactions with the polymers or the poor dispersion of the clay, which could produce clay agglomerations in the surface areas. ${ }^{30,31}$

The presence of eugenol in bionanocomposites does not affect the roughness (only a $5 \%$ increase), which would be attributed to the fact that it is retained inside the polymeric material.

Table 1. Surface roughness and mean square roughness for PHB, the PHBTPS blend, and thePHB- TPS /OMMT, and PHB- TPS/OMMT/Eug bionanocomposites.

\begin{tabular}{|l|c|c|}
\hline \multicolumn{1}{|c|}{ Sample } & $\begin{array}{c}\text { Average surface } \\
\text { Roughness (Ra) } \\
\text { (nm) }\end{array}$ & $\begin{array}{c}\text { Root mean square } \\
\text { (RMS) roughness } \\
\text { (nm) }\end{array}$ \\
\hline PHB & $13.0 \pm 5.3$ & $20.4 \pm 6.1$ \\
\hline PHB-TPS & $18.9 \pm 2.9$ & $24.6 \pm 4.1$ \\
\hline PHB- TPS/OMMT (3\%) & $21.6 \pm 2.4$ & $29.1 \pm 2.8$ \\
\hline PHB- TPS/OMMT (3\%) /Eug (2.5\%) & $20.8 \pm 3.4$ & $28.9 \pm 4.9$ \\
\hline PHB- TPS/OMMT (3\%)/Eug (3\%) & $22.8 \pm 7.7$ & $32.5 \pm 14.2$ \\
\hline
\end{tabular}

\subsection{Nanomechanical properties}

The surface mechanical properties of a polymeric material such as elastic modulus and hardness (represents the resistance of the material to penetration and scratching) were studied by nanoindentation. Figure 3 shows the different indentations made in a PHB sample, with a $5 \times 5$ matrix (25 indentations).

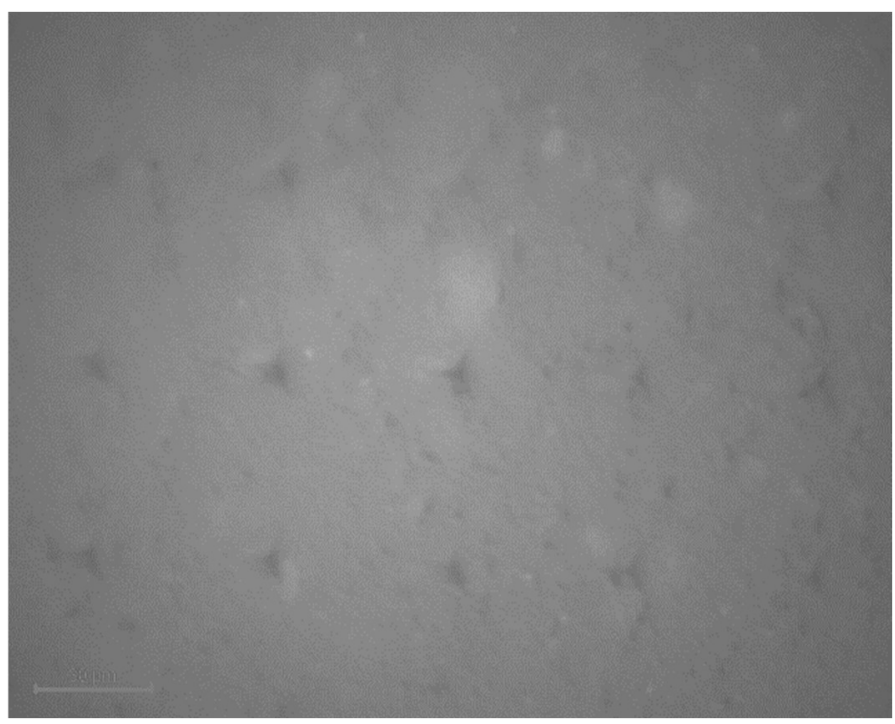

Figure 3. Matrix of nanoindentations performed on a PHB sample.

Figure 4 shows the load-discharge curves for PHB, the PHB- TPS blend, and the bionanocomposites with different eugenol concentrations (applied load $12400 \mathrm{mN}$ ). In this figure, the displacement (penetration of the indenter) of the blend and the bionanocomposite increases in comparison with that of the PHB. The displacement is directly related to the contact area for a defined indenter.According to equation 3 , the hardness is inversely proportional to the area under the load-displacement curve. 


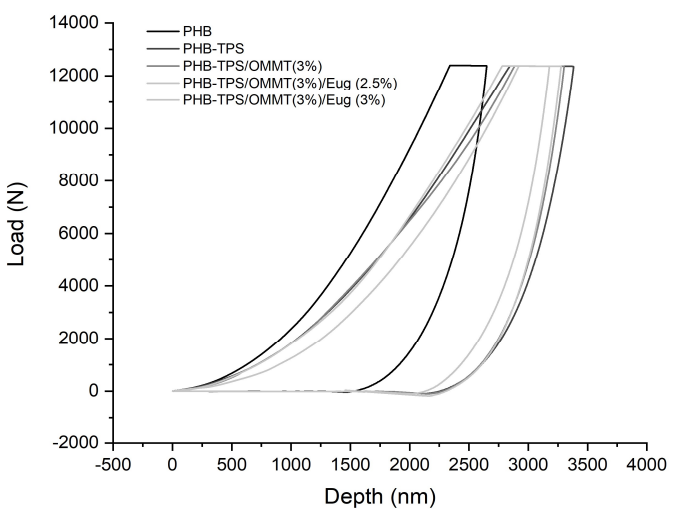

Figure 4. Load-displacement indentation curves for PHB, blend, and bionanocomposites with and without eugenol.

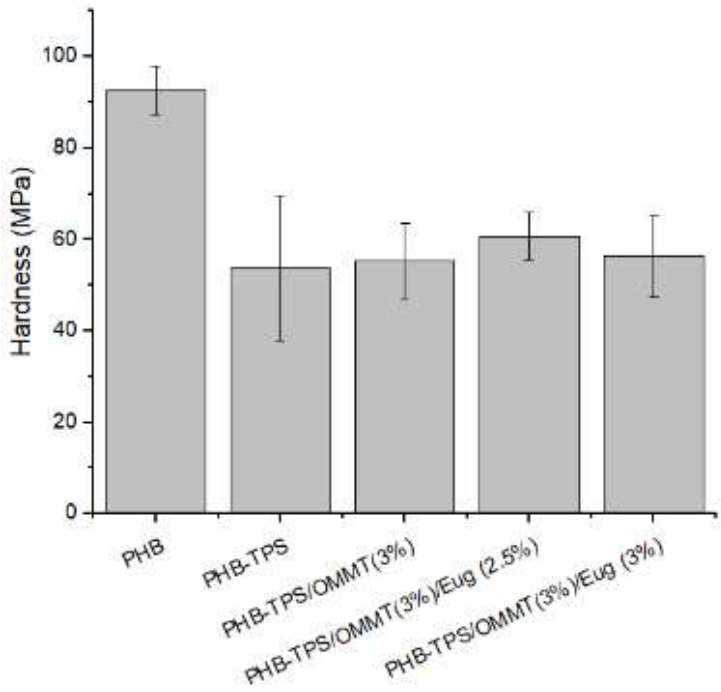

Figure 5 (a) shows a hardness of 92.6 MPa for PHB (maximum displacement of $2647 \mathrm{~nm}$ ) and $53.7 \mathrm{MPa}$ for PHB-TPS (maximum displacement of $3382 \mathrm{~nm}$ ), indicating less resistance to penetration. The difference in hardness between PHB- TPS and PHB mixture is attributed to the presence of starch in the blend, as it is a softer polymer material than PHB. ${ }^{32}$ The bionanocomposites showed a slight increase in hardness compared to the PHB- TPS blend but the presence of eugenol did not show significant changes in hardness

On the other hand, figure $5 \mathrm{~b}$ ) also shows the elastic modules obtained by nanoindentation: 2.26 GPa for the PHB, from 1.46 GPa for the PHB- TPS blend. The bionanocomposites showed a $10 \%$ increase in the elastic module with respect to the PHB-TPS mixture and a $28 \%$ decrease with respect to the PHB, thus increasing the rigidity of the blend when incorporating the clay. The decrease in the elastic module is attributable to the presence of TPS, which is a more flexible polymer than PHB. ${ }^{32}$

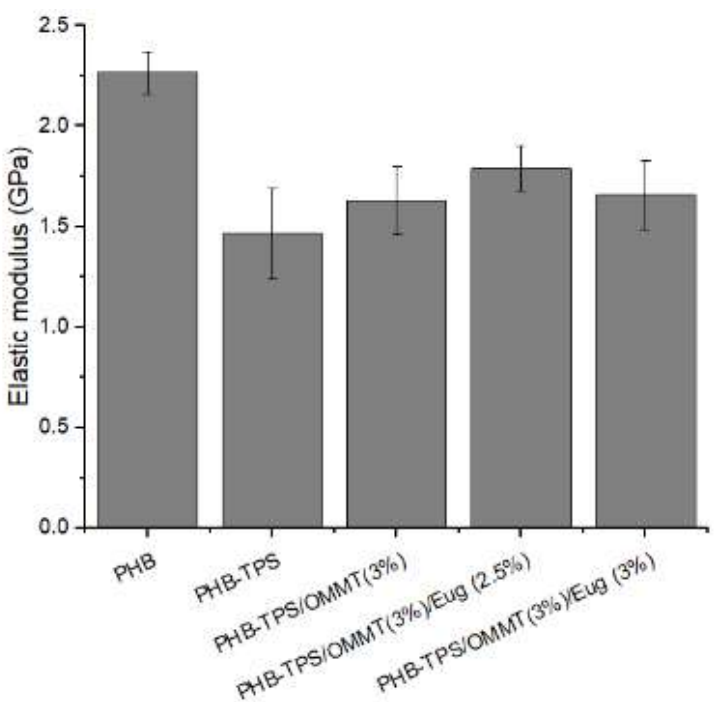

Figure 5. a) Hardness and b) elastic module obtained by nanoindentation for PHB, PHB-TPS mixture and the different bionanocomposites.

The difference between the elastic module of the bionanocomposites and the PHB-TPS blend is minimal. This slight difference would be attributed to the fact that the area analyzed by nanoindentation is more representative of the mixture than of the bionanocomposites, which is attributed to a low dispersion of the clay. ${ }^{33}$

\subsection{Thermo-mechanical properties}

The mechanical properties of a polymer are strongly influenced by temperature, which influences a decrease in the rigidity of the material and an increase in its viscous flow. These variations are reflected in the storage modulus $\left(E^{\prime}\right)$, loss modulus $\left(E^{\prime \prime}\right)$ and loss factor $(\tan \delta)$. These factors were determined by DMTA. When analyzing the loss factor $(\tan \delta)$, secondary transitions such as the glass transition temperature (Tg) are observed, so DMTA is a more sensitive technique than DSC.

Figure 6 shows that at low temperatures, the TPS $\left(-100^{\circ} \mathrm{C}\right)$ behaves the same as a rigid polymer with an E' of approximately $16000 \mathrm{MPa}$ as opposed to $\mathrm{PHB}$ with an $\mathrm{E}^{\prime}$ of $4000 \mathrm{MPa}$. Whereas the storage module reflects the ability of a material to store mechanical energy without dissipation and to resist deformation, TPS at temperatures below $-70^{\circ} \mathrm{C}$ is more resistant to deformation and, therefore, more rigid than blend and bionanocomposites. But then it has a pronounced drop at approximately $-50^{\circ} \mathrm{C}$ and starts to behave as a polymer with a low resistance to deformation or is more flexible. On the other hand, PHB shows a gentle decrease in modulus with temperature associated with increased chain movement. ${ }^{34}$

In the PHB- TPS blend, the value of E' (6409 MPa) is consistent with the PHBTPS ratio (65:35) contained in the mixture. Bionanocomposites show an $E^{\prime}$ of $7700 \mathrm{MPa}$ more than the PHB-TPS blend. This increase is attributable to the high stiffness and aspect ratio of the nano-filler. In addition to the good affinity through interfacial interaction between the polymers and the dispersed clay. ${ }^{35}$

Between the different bionanocomposites, PHB-TPS /OMMT(3\%) presented the highest $\mathrm{E}^{\prime}$ in the whole temperature range up to approximately $50^{\circ} \mathrm{C}$. Above $50{ }^{\circ} \mathrm{C}$, there is no significant difference between the $\mathrm{E}^{\prime}$, which would indicate that the amount of TPS, clay, and eugenol do not influence the ability of PHB to resist deformation from that temperature.

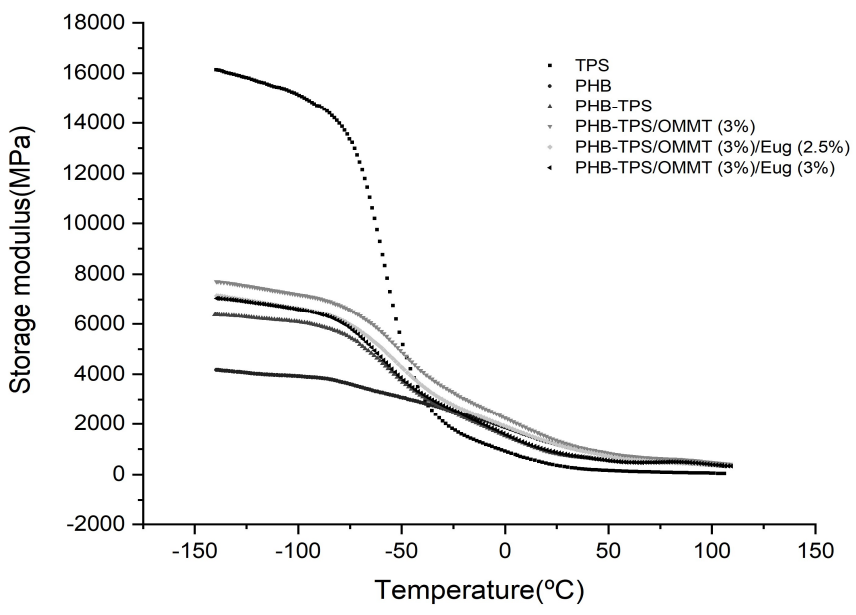

Figure 6. Variation of storage modulus vs. temperature for TPS, PHB, PHBTPS blend and bionanocomposites; frequency $10 \mathrm{~Hz}$. 
Another parameter that can be determined is the loss module that reflects the ability of the materials to dissipate energy. Figure 7 shows the transitions related to the amorphous region of the polymers (secondary transition). Molecular movements are activated in this area, although the movements occur with difficulty, producing molecular friction dissipating much of the effort as heat, leading to an increase in the modulus of loss.

The loss module of the TPS is $1714 \mathrm{MPa}$, which indicates that it has a high dissipation capacity. Furthermore, this peak (see Figure 7) is attributed to the relaxation $\beta 1$ of plasticized starch and originates from the partial miscibility of glycerol and starch, specifically the relaxation $\beta 1$ corresponding to the glycerolrich phase (pure glycerol has a transition of $-78^{\circ} \mathrm{C}$ ).$^{36}$ For the mixture PHB-TPS and the bionanocomposite PHB-TPS /OMMT(3\%)/ Eug (3\%) the transition attributed to starch still appears at $-57^{\circ} \mathrm{C}$, but with a decrease in the loss module of $410 \mathrm{MPa}$ for the bionanocomposite with 3\% eugenol and of $592 \mathrm{MPa}$ for the blend. The decrease in the intensity of the PHB- TPS transition is attributed to the contribution of the PHB in the blend since the PHB has a lower modulus of loss (dissipates less energy) compared to the TPS that has a higher modulus (dissipates more energy).

For PHB-TPS /OMMT(3\%) and PHB- TPS /OMMT(3\%)/ Eug (2.5\%), the transition was displaced to higher temperatures $\left(-50^{\circ} \mathrm{C}\right)$ since the movement of glycerol $(\beta 1)$ produced by the molecular interactions between TPS-PHB and TPS-Clay was restricted. The loss module for the bionanocomposites was 409 $\mathrm{MPa}$ and $412 \mathrm{MPa}$ for the bionanocomposites with $2.5 \%$ eugenol, these values indicate that the bionanocomposites does not show a significant difference in loss module, evidencing that all present the same capacity to dissipate energy.

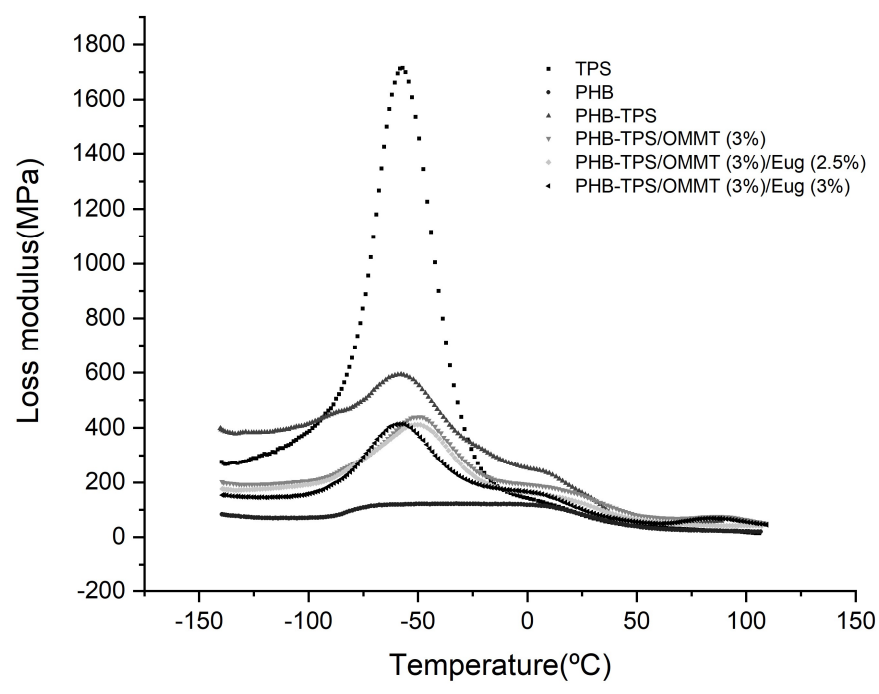

Figure 7. The loss modulus of TPS, PHB, PHB-TPS blend and bionanocomposites. Frequency $10 \mathrm{~Hz}$.

Tan delta, damping factor, provides information about the energy lost in a system due to deformation and is related to the impact resistance of a polymer material. Figure 8 shows that the maximum intensity of TPS is related to relaxation $\beta 1\left(45^{\circ} \mathrm{C}\right)$. For PHB-TPS and bionanocomposites, a decrease in intensity is observed, which would be associated with PHB-clay-eugenol reducing the mobility of starch chains. ${ }^{37}$ This also suggests that when stress is removed, the energy stored in the deformation of the material is recovered more quickly ${ }^{38}$ compared to that of the TPS. It is also observed that $\beta 1$ of the mixture and PHB- TPS /OMMT(3\%)/Eug (3\%) moved at lower temperatures, approximately at $-50{ }^{\circ} \mathrm{C}$, which would indicate that the molecular movement associated with the glycerol-rich phase of TPS is slightly restricted. The PHBTPS /OMMT (3\%) and PHB-TPS /OMMT(3\%)/ Eug (2.5\%) showed no variation $\left(-44^{\circ} \mathrm{C}\right)$.

The PHB shows a relaxation at $16{ }^{\circ} \mathrm{C}$, corresponding to the glass transition temperature (Tg). For PHB- TPS, PHB-TPS /OMMT(3\%), PHB-TPS /OMMT(3\%)/Eug (2.5\%) and PHB- TPS /OMMT(3\%)/ Eug (3\%) the Tg was displaced at higher temperatures, $20^{\circ} \mathrm{C}, 28{ }^{\circ} \mathrm{C}$, and $25^{\circ} \mathrm{C}, 15^{\circ} \mathrm{C}$ respectively. The increase in Tg suggests that the mobility of the chains is restricted due to a homogeneous dispersion of the clay, in addition to the interactions between the load (clay or eugenol) and the polymer matrix, which makes the movement of the chains difficult, thus increasing $\mathrm{Tg} .{ }^{39}$ On the other hand, it was observed in Figure 8 that the $\mathrm{Tg}$ of polymeric materials decreases with the concentration of eugenol. Finally, the PHB-TPS /OMMT (3\%) has the highest Tg, therefore, it can dissipate energy better, which is defined in greater impact resistance at the ambient temperature.

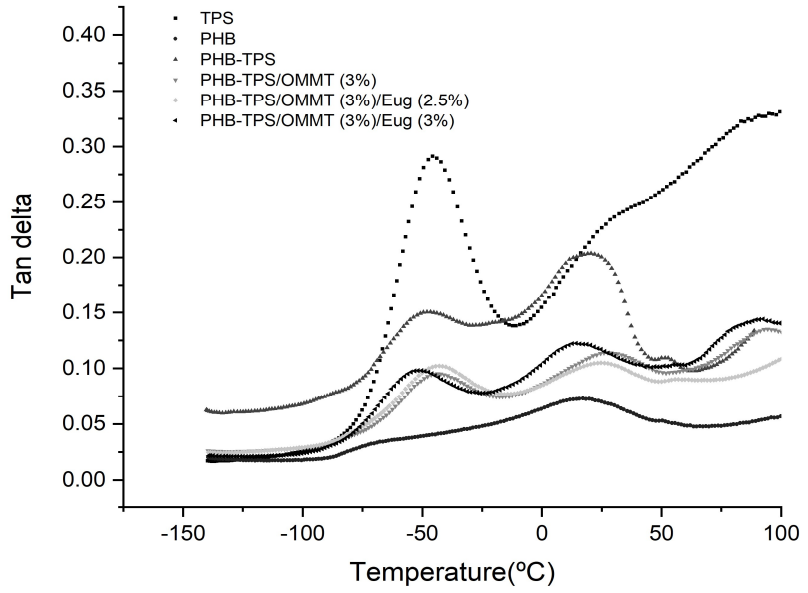

Figure 8. Tan $\delta$ vs temperature for TPS, PHB, PHB-TPS blended bionanocomposites. Frequency $10 \mathrm{~Hz}$.

\section{CONCLUSIONS}

Based on this work devoted to studying the effects of eugenol on the mechanical, thermo-mechanical, and morphological properties of PHB-TPS bionanocomposites, the following conclusions are stablished:

a) Considering the results of XRD and AFM of bionanocomposites, it could be defined that bionanocomposites have a combined morphology (exfoliation-interleaved), which is indicated by the diffractograms obtained and the roughness values. Also, it was determined that eugenol shows no effect on the morphology of bionanocomposites.

b) The loss modulus (E") value of the polymers, the mixture, and the bionanocomposites presents a difference, but the effect of the TPS

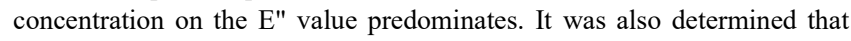
eugenol does not affect this property. On the other hand, the bionanocomposites of PHB-TPS /OMMT (3\%) presented the highest $\mathrm{E}^{\prime}$ in the entire temperature range up to approximately $50^{\circ} \mathrm{C}$, which is attributed to the fact that the clay improves the capacity of PHB to resist deformation, this effect is slightly diminished by increasing the concentration of eugenol, the same effect was determined when the glass transition was analyzed.

c) Finally, from the nanomechanical properties, it was determined that the bionanocomposites with $2.5 \%$ eugenol showed the highest modulus of the bionanocomposites.

\section{ACKNOWLEDGMENTS}

Karla Garrido thanks to Scholarship from CONICYT No 21161368, the Postgraduate School of the University of Concepción, and IMDEA Materials Institute.

\section{REFERENCES}

1. A. A. Shah, F. Hasan, A. Hameed and S. Ahmed, Biotechnol. Adv., 2008, 26, 246-65.

2. P. Europe, Plastics - the Facts 2019, 2019.

3. P. Europe, Plastics-the facts 2017, An analysis of European plastics production, demand and waste data; 2017, 2017.

4. S. Chanprateep, J. Biosci. Bioeng., 2010, 110, 621-632.

5. J. Greene, J. Polym. Environ., 2007, 15, 269-273.

6. S. Sinha Ray and M. Okamoto, Prog. Polym. Sci., 2003, 28, 1539-1641.

7. M. M. Reddy, S. Vivekanandhan, M. Misra, S. K. Bhatia and A. K. Mohanty, Prog. Polym. Sci., 2013, 38, 1653-1689.

8. Y. Dahman and C. U. Ugwu, Bioprocess Biosyst. Eng., 2014, 37, 1561-8. 
9. M. C. S. Corrêa, M. C. Branciforti, E. Pollet, J. a. M. Agnelli, P. a. P. Nascente and L. Avérous, J. Polym. Environ., 2011, 20, 283-290.

10. G. Chen, G. Hao and T. Guo, J. Mater. Sci. Lett., 2002, 21, 1587-1589.

11. A. Botana, M. Mollo, P. Eisenberg and R. M. T. Sanchez, Appl. Clay Sci. J., 2010, 47, 263-270.

12. E. Panayotidou, A. Baklavaridis, I. Zuburtikudis and D. S. Achilias, J. Appl. Polym. Sci., 2015, 132, 1-8.

13. D. a. D'Amico, L. B. Manfredi and V. P. Cyras, Thermochim. Acta, 2012, 544, 47-53.

14. A. Giannakas, P. Stathopoulou, G. Tsiamis and C. Salmas, J. Food Process. Preserv., 2019, 1-15.

15. S. Tunç and O. Duman, LWT - Food Sci. Technol., 2011, 44, 465-472.

16. M. Abdollahi, M. Rezaei and G. Farzi, J. Food Eng., 2012, 111, 343-350.

17. K. A. Garrido-Miranda, B. L. Rivas, M. A. Pérez -Rivera, E. A. Sanfuentes and C. Peña-Farfal, LWT - Food Sci. Technol., 2018, 98, 260-267.

18. V. H. Campos-Requena, B. L. Rivas, M. A. Pérez and E. D. Pereira, Polym. Int., 2016, 65, 483-490.

19. V. H. Campos-Requena, B. L. Rivas, M. A. Pérez, C. R. Figueroa, N. E. Figueroa and E. A. Sanfuentes, Postharvest Biol. Technol., 2017, 129, 2936.

20. S. Beigzadeh Ghelejlu, M. Esmaiili and H. Almasi, Int. J. Biol. Macromol., 2016, 86, 613-621.

21. W. C. Oliver and G. M. Pharr, J. Mater. Res., 1992, 7, 1564-1583.

22. S. Bruzaud and A. Bourmaud, Polym. Test., 2007, 26, 652-659.

23. D. M. Panaitescu, C. A. Nicolae, A. N. Frone, I. Chiulan, P. O. Stanescu, C. Draghici, M. Iorga and M. Mihailescu, J. Appl. Polym. Sci., 2017, 134, 1-14.

24. M. a. Abdelwahab, A. Flynn, B.-S. Chiou, S. Imam, W. Orts and E. Chiellini, Polym. Degrad. Stab., 2012, 97, 1822-1828.
25. M. Zhang and N. L. Thomas, J. Appl. Polym. Sci., 2009, 116, 688-694.

26. A. Arora and G. W. Padua, J. Food Sci., 2010, 75, R43-9.

27. M. Farmahini-Farahani, A. Khan, P. Lu, A. H. Bedane, M. Eic and H. Xiao, Appl. Clay Sci., 2017, 135, 27-34.

28. R. Hajiraissi and M. Parvinzadeh, Appl. Surf. Sci., 2011, 257, 8443-8450.

29. K. A. Garrido-Miranda, B. L. Rivas and M. A. Pérez, J. Appl. Polym. Sci., 2017, 134, 45217.

30. M. Parvinzadeh, S. Moradian, A. Rashidi and M.-E. Yazdanshenas, Polym. Plast. Technol. Eng., 2010, 49, 874-884.

31. M. Ataeefard and S. Moradian, Appl. Surf. Sci., 2011, 257, 2320-2326.

32. R. M. S. M. Thiré, T. A. A. Ribeiro and C. T. Andrade, J. Appl. Polym. Sci., 2006, 100, 4338-4347.

33. L. Zaidi, S. Bruzaud, M. Kaci, A. Bourmaud, N. Gautier and Y. Grohens, Polym. Degrad. Stab., 2013, 98, 348-355.

34. J. Adam, B. A. Korneliusz and M. Agnieszka, J. Appl. Polym. Sci., 2013, 130, 3175-3183.

35. J.-W. Rhim, H.-M. Park and C.-S. Ha, Prog. Polym. Sci., 2013, 38, 1629 1652.

36. H. M. Wilhelm, M. R. Sierakowski, G. P. Souza and F. Wypych, Carbohydr. Polym., 2003, 52, 101-110.

37. F. Ivanič, D. Jochec-Mošková, I. Janigová and I. Chodák, Eur. Polym. J., 2017, 93, 843-849.

38. A. M. Díez-Pascual and A. L. Díez-Vicente, ACS Appl. Mater. Interfaces, 2014, 6, 9822-34.

39. Y. Q. Zhang, J. H. Lee, J. M. Rhee and K. Y. Rhee, Compos. Sci. Technol., 2004, 64, 1383-1389. 